\title{
Jesús Ignacio Delgado Rojas, Ciudadanía liberal y moralismo legal
}

(2021) Centro de Estudios Políticos y Constitucionales

Madrid, 564 pp.

Óscar Buenaga Ceballos

Abogado. Doctor en Derecho

ORCID ID 0000-0001-8541-7398

buenaga@gmail.com

Cita recomendada:

Buenaga Ceballos, Ó. (2021). Jesús Ignacio Delgado Rojas, Ciudadanía liberal y moralismo legal. Eunomía. Revista en Cultura de la Legalidad, 21, pp. 479-482.

doi: https://doi.org/10.20318/eunomia.2021.6380

Recibido / received: 08/09/2021

La editorial Centro de Estudios Políticos y Constitucionales acaba de publicar dentro de su prestigiosa colección El Derecho y la Justicia, dirigida por Elías Díaz y Francisco J. Laporta, el libro Ciudadanía liberal y moralismo legal, del profesor de Filosofía del Derecho de la Universidad Carlos III de Madrid Jesús Ignacio Delgado Rojas. El libro tiene su origen en la tesis defendida por el autor en dicha Universidad en el año 2019, dirigida por Eusebio Fernández García -que también prologa el libro-, habiendo obtenido la máxima calificación de Sobresaliente Cum Laude, además de las Menciones de doctorado internacional y la especial del Premio Luis Díez del Corral, concedido por el Centro de Estudios Políticos y Constitucionales a las mejores tesis en Historia de las Ideas y de las Formas Políticas, Teoría Política Normativa y Filosofía Política.

Desde mi doble condición de abogado profesional y de doctor en Filosofía del Derecho me resulta imposible valorar cualquier libro proveniente del ámbito teórico del Derecho sin, al mismo tiempo, considerar si puede tener algún tipo de repercusión sobre la vertiente práctica, y he de adelantar desde ya que este la tiene, como 
expondré. Se trata de un libro de Filosofía política que analiza el que, probablemente, sea uno de los problemas más debatidos en las siempre procelosas relaciones entre el Derecho y la Moral, cual es el de la imposición de esta mediante el Derecho y los efectos que, consecuentemente, tiene este empleo de las normas jurídicas sobre la autonomía individual.

Es evidente que todo Derecho constituye un instrumento limitador de las diferentes libertades individuales y que una convivencia social pacífica y ordenada sólo se consigue coordinando aquellas mediante el uso de la coacción, que constituye el recurso típico necesario para lograr la eficacia normativa. La cuestión surge cuando atendemos al contenido de las normas jurídicas, que, o bien está conectado con la Moral, o bien es organizativo (neutro moralmente), pero con una coactividad sustentada en razones morales. Es en este punto, cuando, en mi opinión, cualquier análisis filosófico-jurídico se encuentra con el problema básico a resolver en el examen de las relaciones Derecho-Moral: determinar con la suficiente precisión dentro de la Moral general el ámbito que ocupa la virtud de la justicia. No todo lo moralmente bueno es moralmente justo (pero sí todo lo justo es moralmente bueno), pues existen multitud de conductas morales irrelevantes desde la óptica de la justicia. Hay acciones malvadas que no son moralmente injustas, por mucho reproche moral que puedan recibir. Precisamente, a partir de este planteamiento se vislumbra quizá con mayor nitidez el fenómeno del moralismo legal en torno al cual gira el libro de Delgado Rojas. En este sentido, cuando el Derecho se utiliza como instrumento para imponer no sólo la parte de la Moral atinente a la justicia, sino otros contenidos que hacen referencia a lo que el Poder gobernante (incluso aunque cuente con legitimación democrática) entienda como modelo moral de vida buena, virtuosa o perfecta, tiene lugar una inevitable restricción de la libertad individual que no se encuentra justificada en términos morales de justicia, constituyendo, por lo tanto, una extralimitación del Derecho de sus fines justos. Más aún, la imposición de una determinada moral sin anclaje en la justicia puede suponer una vulneración de esta última, ya que la autonomía del individuo se ve constreñida de modo que los valores de la dignidad y libertad resultan afectados, produciéndose un claro conflicto moral.

Delgado Rojas explica este fenómeno muy bien. En sus Reflexiones finales aclara que «son cosas distintas: por un lado, la justificación moral del Derecho y la posibilidad de hacer juicios morales sobre él y, por otro, que el Derecho pueda utilizarse para imponer ese juicio moral» (p. 531). A su entender-que respaldo plenamente-, el Derecho debe ceñirse respecto de sus contenidos morales, a «una ética jurídica que no se confunda con el moralismo legal», que «sólo puede ser una ética de mínimos de vocación objetiva y universalizable. Los derechos humanos fundamentales, junto con los deberes inherentes exigibles a todo individuo, serían el mejor contenido -y único posible- para integrar ese consenso mínimo pero exigible» (Reflexiones finales, p. 530). El autor se decanta por la defensa de un modelo de ciudadanía liberal -como reza el título de la obra- en la línea de un liberalismo igualitario, que fundamenta sólidamente sobre la idea kantiana de dignidad humana y la rawlsiana de autorrespeto.

Por otro lado, de la estructura de la obra, particularmente destacaría su original modo de presentación del debate entre las posiciones liberales y conservadoras (defensoras estas del moralismo legal en sus diversas variantes), por cuanto la primera parte nos ofrece una descripción general de las posturas en conflicto con el suficiente detalle para permitirnos entrar debidamente informados en los dos debates concretos y modélicos que examina en la segunda parte. El primero de estos es el producido entre John Stuart Mill y el juez James Fitzjames Stephen (figura bastante desconocida en nuestro país, cuya introducción es mérito del libro ahora examinado) en el siglo XIX, en tanto que el segundo ya tuvo lugar en el siglo XX entre H.L.A. Hart 
y el juez Patrick Devlin. Ambos debates, que el autor expone con todo lujo de datos, incluso biográficos, nos desvelan la riqueza de la polémica entre posiciones liberales y conservadoras en dos épocas diferentes, aportando una visión que es muy de agradecer para los prácticos del Derecho. Considero que, en general, este es el enfoque más adecuado para los libros de Filosofía jurídica, relacionando los debates teóricos o ideológicos con problemas acontecidos en la realidad, con el Derecho 'de carne y hueso'. Finalmente, la tercera parte del libro ofrece una magnífica panorámica de las cuatro grandes corrientes que sustentan posiciones enmarcables dentro del moralismo legal, como son el populismo moral, el perfeccionismo, el paternalismo y el comunitarismo.

También he de destacar que la obra me ha parecido rigurosa en su exposición, pero, además, muy sugerente. Personalmente, me ha reafirmado en la postura $-y$ creo que el autor del libro la compartirá- de que el valor moral de la justicia es el que debe dirigir y limitar la creación y aplicación del Derecho, incluso contra 'excesos' morales, impidiendo que las normas jurídicas regulen y asuman cualquier otro objetivo relacionado con el resto de la Moral. Es decir, prima facie, me parece injustificado que el Derecho nos imponga -o promueva- cualquier tipo de ideología política, creencia moral o religiosa acerca de cómo debemos vivir y hemos de llevar a cabo nuestro proyecto personal de vida buena y lograr la felicidad o la perfección moral. Siempre que respetemos la moralidad mínima que impone la justicia (respetar la dignidad y libertad, propia o ajena, y todo lo que conlleva), el cumplimiento del resto de la moralidad es cosa nuestra, sin que necesitemos un Derecho vigilante de tales cuestiones. El principio de autonomía o de libertad general que ostentamos por el mero hecho de ser personas (la idea de dignidad que tan magistralmente configuró Kant) deslegitima a cualquier Derecho que pretenda limitar nuestra libertad más allá de su cometido, dirigido, pero también limitado, por la justicia. El Derecho no es un mecanismo diseñado para homogeneizar la sociedad -tendería entonces, por definición, a eliminar todo atisbo de pluralismo-, sino para evitar que esta se destruya, prohibiendo un conjunto de conductas dañosas graves (que son inmorales en cuanto malvadas, sin duda). En suma, entiendo que ha de haber un moralismo legal necesario cuando identificamos esta moralidad con el contenido de la justicia, pero tiene que haber igualmente un moralismo legal vedado respecto del contenido de la Moral que exceda de lo justo. La moralización que pretende un Derecho justo no consiste en que los ciudadanos seamos ejemplares, excelentes o educados, sino que no crucemos la línea donde comienzan las acciones malvadas graves, que son aquellas que dañan la dignidad y la libertad de nuestros congéneres e incluso las nuestras. En este punto, posturas liberales y defensoras del moralismo legal estarían de acuerdo en recoger esta moral necesaria, pero a partir de aquí, estas últimas quieren dar un paso más e 'intervenir' en la vida moral de los ciudadanos, donde multitud de alternativas justas son posibles. En mi opinión, el Derecho no está para incluir como parte de sus contenidos los dictados morales que provengan de ninguna revelación religiosa o tradición, ni tampoco de un ideal modélico de sujeto con arreglo a un código moral imperante en una sociedad determinada. $Y$ el libro de Delgado Rojas aporta muchas y buenas razones que apuntan en esta dirección desmoralizante del Derecho, para ceñirlo a sus fines justos.

En resumen, se trata de un libro de Filosofía jurídico-política que nos expone el debate entre las dos posturas paradigmáticas del liberalismo y el conservadurismo en torno a los diferentes modos de entender la función del Derecho respecto de la Moral, pero descendiendo a polémicas reales (tan actuales como la de la homosexualidad), lo que le convierte en una obra útil no sólo, obviamente, para los especialistas académicos, sino también para los prácticos del Derecho, que en la cotidiana tarea de interpretar y aplicar las normas jurídicas y de argumentar en el foro nos vemos obligados a realizar continuos razonamientos morales sobre ellas (sobre 
lo justo, pero también sobre lo bueno en general), y útil también para cualquier profesional de la Política que quiera profundizar en sus argumentos a la hora de abordar un problema social con el suficiente rigor y adoptar una decisión pública acertada. Un libro, pues, altamente formativo, tanto a nivel teórico como práctico, dado que, a buen seguro, enriquecerá de un modo notable nuestra capacidad de argumentación jurídica. 